\title{
Obituary
}

\section{Professor Adel Abdel Fattah Mahmoud (1942-2018)}

The medical communityin Egyptand the world has lost one of the greatest scientists, Prof Adel Mahmoud; professor of Tropical Medicine \& Immunology and creator of important vaccines that saved many lives, $\mathrm{He}$ has many important scientific publications including text books, research papers and projects' reports. Among his great preventive products was the combined child vaccine containing Mumps, Measles, Rubella and Chicken Pox. Also was credited with the production of the Rota virus and the HPV vaccines. Healso suggesteda road map for global new vaccines development and production.

Professor A Mahmoud is an Egyptian born, graduated from Egyptian schools and Universities, qualified and specialized with British degrees. He lived and served in American Universities as well as working in multinational and international foundations.

Egyptian Community Medicine Association (ECMA) is blessing heavenly the soul of late professor Adel Mahmoud and will highlights on stages and credits of his life.

- He was born in Cairo in 1941

- Studied in Cairo medical school, MBBCH in 1963

- Worked as a Public health assistant lecture in Ain-Shams university 1965

- Studied In London School of hygiene \& tropical medicine, PhD in 1972

- Joined Case western school, University of Cleveland, USA. 1973-1998 and was upgraded to be the head of the department of Tropical medicine 
- Worked in Merck multinational company of vaccines 1998-2006 till he reached the post of the chair man of the company

- Joined Princeton university, worked in molecular biology, 2006 till he passed in June 2018

The Lancet Journal and Bill Gate founder of Microsoft have valued him as a great scientist and creator of important vaccines

\section{Bill Gates}

@BillGates

Earler this month, the world lost one of the greatest vaccine creators of our time. Dr. Adel Mahmoud saved the lives of countless children. b-gat.es/2tr8KDZ

10:20 PM - Jun 21, 2018

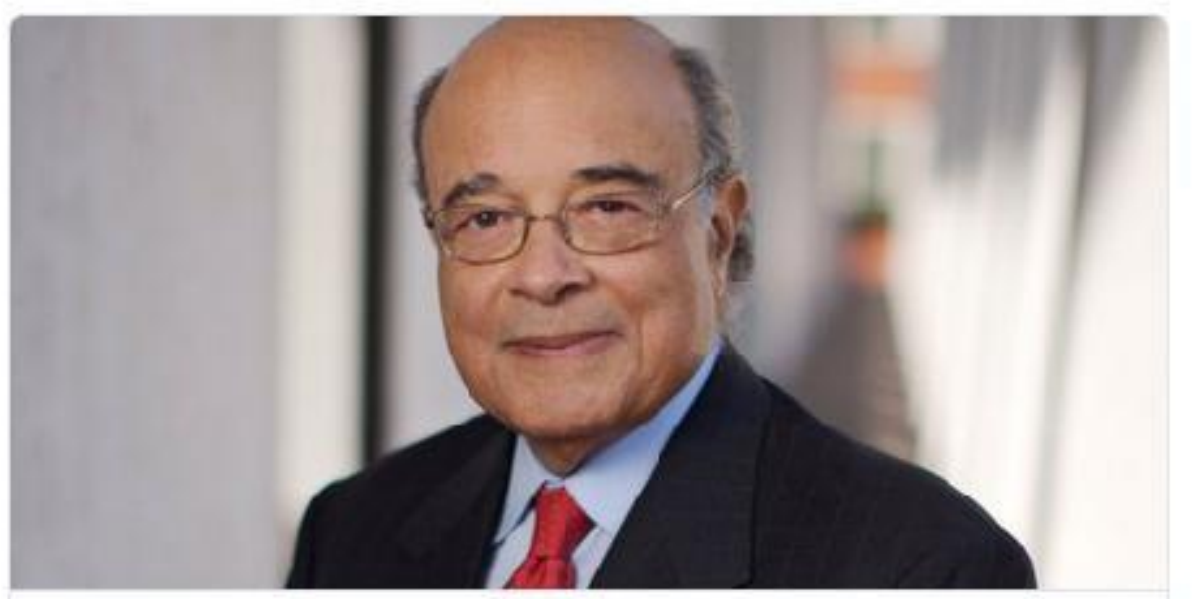

Dr. Adel Mahmoud, Who Was Credited With HPV and Rotavi... As president of Merck Vacr.ines, Dr Mahmoud overcame doubts in developing vaccines against two threats to women and babies: HPV nytimes.com 
Egyptian Minister of Immigration Nabila Makram, and Minister of Higher Education Khaled Abdel Ghaffar released statements mourning the death of Dr. Mahmoud, the leading researcher of vaccines and infectious diseases who spent his life developing vaccines that saved the lives of hundreds of millions around theworld.

May god bless the soul of Professor Adel Mahmoud and send him to heaven 